\title{
Approach to Electromagnetic Control of the Extreme Positions of a Piston in a Free Piston Generator
}

\author{
Dmitry Petrichenko ${ }^{1}$, Alexey Tatarnikov ${ }^{1} \&$ Igor Papkin $^{1}$ \\ ${ }^{1}$ Federal State Educational Institution of Higher Professional Education, Moscow state university of mechanical \\ engineering (MAMI), 107023, Moscow, Russia \\ Correspondence: Dmitry Petrichenko, Federal State Educational Institution of Higher Professional Education, \\ Moscow state university of mechanical engineering (MAMI), st. Bolshaya Semenovskaya, 38, 107023, Moscow, \\ Russia. E-mail: dmitry.petrichenko@gmail.com
}

Received: October 4, 2014

doi:10.5539/mas.v9n1p119
Accepted: October 8, 2014 Online Published: December 2, 2014

URL: http://dx.doi.org/10.5539/mas.v9n1p119

\begin{abstract}
This paper presents an approach to controlling the extreme positions of a piston in a free piston generator using linear electrical machine. The machine is used to provide the proper compression ratio necessary for ignition and limit the stroke of the piston in expansion phase. A Matlab/Simulink model, implementing the entire system, is presented. The results of simulation of the system show stable power generation within required movement boundaries of the piston.
\end{abstract}

Keywords: free piston generator, free piston engine, opposed free piston generator, linear generator, linear alternator, electromagnetic control, free piston Simulink model, dynamic simulation

\section{Introduction}

The concept of a free piston engine is quite old and leads us back to the 1930s when it was first proposed. Such engines were mostly used in the period up to 1960s as air compressors and gas generators. A good review of the free piston engine history is given in (Mikalsen \& Roskilly, A review of free-piston engine history and applications., 2007). The historical free piston engines were mostly of opposed piston type and had mechanical linkage between two pistons in order to balance it and prevent vibrations. They had several advantages over rotational engines, and the main advantage was compactness of the units and a perfect dynamic balance.

Nowadays we can witness a strong growth of interest to free piston generators. The use of that type of engines allows maximizing the efficiency and minimizing losses in energy conversion. A lot of works are devoted to the problems of calculation and development of that type of generators in application to hybrid vehicles and range extenders, e.g. (Ferrari \& Friedrich, 2012), (Carter \& Wchner, 2003), (Kosaka, et al., 2014), (Waqas, Backstrom, Thelin, \& Sadarangani, 2002), (Mikalsen \& Roskilly, A review of free-piston engine history and applications., 2007), (Kock, Haag, \& Friedrich, 2013), (Hibi \& Ito, 2004), (Zhaoping \& Siqin, 2010). The absence of mechanical limits in a general scheme of a free piston engine leads to the complexity of its control. The control methods and approaches are presented in many papers. Some of them are concentrating on control system development, as (Nemecek, Sindelka, \& Vysony, 2006), (Ibrahim, Aziz, Abidin, \& Zulkifi, 2011), (Zulkifli, Karsiti, \& A-Aziz, 2009), (Goto, Moriya, Kosaka, \& Akita, 2014), (Mikalsen \& Roskilly, The control of a free-piston engine generator. Part 2: engine dynamics and piston motion control., 2010). The others highlighting simulation approach (Pohl \& Graf, 2005), (Li, Luan, Wang, \& Deng, 2010), (Larmi, Isaksson, Tikkanen, \& Lamiila, 2001), (Shourky, Taylor, Clark, \& Famouri, 2002), (Goldsborough \& Van Blarigan, 2001), (Mikalsen \& Roskilly, 2008).

The free piston engines do not have a crankshaft, which means that the piston motion is not restricted mechanically and determined only by the interaction of the forces on the translator. Since the pistons and translator, holding quite a big mass, are reciprocating, we need to control and limit the extreme positions of the pistons. We must assure that the TDC is achieved along with the required compression ratio. Besides, we must assure that the piston doesn't clap the cylinder head. From the one hand, we must provide the full stroke of the translator in order to make the intake and exhaust windows open. From the other hand, we must not allow the translator fly out from the engine. 
In a real engine, the piston forces may vary from cycle to cycle depending on different circumstances, including the ignition drop.

The aim of this study is to define a method that allows controlling flexibly the top dead center (TDC) and bottom dead center (BDC) of the free piston linear generator working with permanent magnet synchronous machines.

\section{Construction and Simulation Approach}

\subsection{Free Piston Engine Construction}

There are different free piston engine configurations that are well known nowadays. Mainly they are of single piston and dual piston types. Single piston engine consists of a single cylinder and a piston. The last is connected to a translator of a linear electrical machine. The electrical machine is pushing the piston in the compression phase, achieving the desired compression ratio. After ignition in the expansion phase the electrical machine is breaking the piston, thus, generating the energy.

Dual piston free piston engines contain two cylinders with two pistons. The electrical machine is placed between the two pistons. While one cylinder is in compression phase, the other one is in expansion phase. The part of the expansion energy is used to achieve the desired compression ratio in the opposite cylinder, while the rest of the energy is converted into electricity.

Another type of a dual piston engine is an opposed free piston engine. A drawing of the opposed piston free piston engine being described in this paper is presented in the

Figure 1. It contains two electrical machines 1, translator director 2, where the translator 3 slides, and pistons 4. The right side of the engine is symmetrical to the left one relative to the vertical axis, except the size of the exhaust windows 9. The movement of the pistons is synchronized, thus the inertia forces are balanced. As soon as the engine is started, the electrical machines 1 are moving the pistons towards each other, closing the intake windows 5 and exhaust windows 9, compressing the air and delivering fuel into the combustion chamber through the jet 8 . As soon as the defined compression ratio is achieved at the top dead center (TDC), the fuel mixture is ignited that leads to the growth of the pressure in the cylinder. The pressure forces the pistons to move from each other, moving also the translator of the electrical machines. During this part of the cycle the electrical machines are producing energy. In this study, we use permanent magnet linear machines as actuator and generator.

\subsection{Free Piston Engine Model}

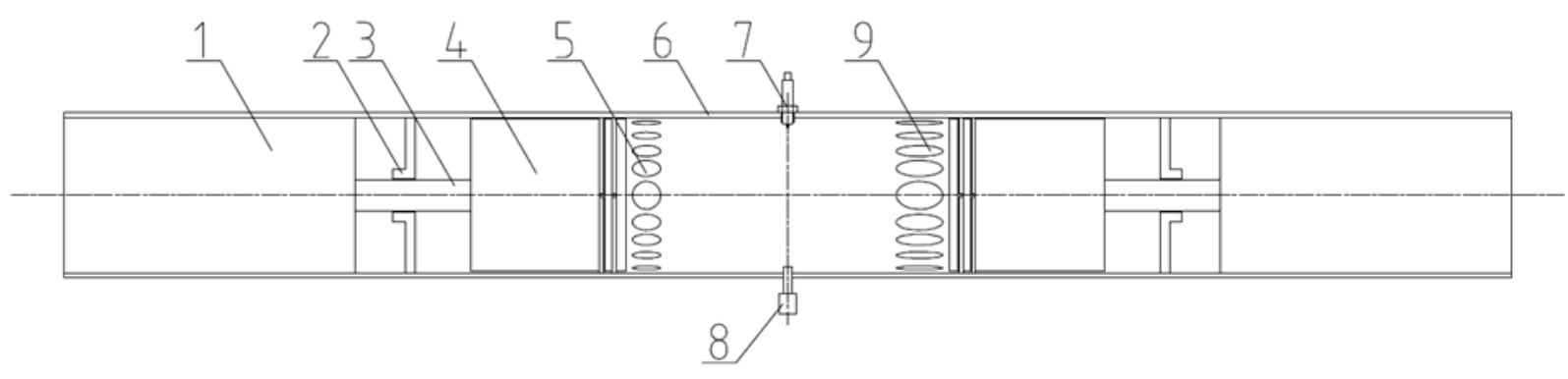

Figure 1. A drawing of the opposed-piston free piston engine

The dynamics of the piston is the main thing that differs a free piston engine from a conventional one. In conventional engines the piston motion profile is determined by the crank system. Due to high inertia of the mechanical system, the rotational speed of the conventional engine remains constant in the time frame of one cycle. From the other hand, in the free piston engine, the piston motion is determined by the instantaneous balance of the forces on the translator at any point in the cycle. That means that the combustion process in the cylinder influences the speed of expansion and the piston motion profile depends on different operating conditions and may vary a lot. Besides, the dynamic characteristics of the translator of a linear electrical generator that is directly linked to the piston have a high influence on piston dynamics.

We perform the coupled simulation of the entire system: free piston engine - electrical drive. The model that we used in our study of the free piston engine is based on its pressure diagram. We performed the calculation of the diagram parameters having the following dimensions and parameters of the free piston engine:

- $\quad D$ - cylinder diameter, $\mathrm{m}$ 
- $S$ - piston stroke, $\mathrm{m}$

- $K_{c}$ - compression ratio

- $\lambda$ - pressure ratio

Piston surface is determined as following:

$$
S_{\text {pist }}=\frac{\pi D^{2}}{4}
$$

Considering two pistons in on cylinder we can obtain a formula for the general cylinder volume:

$$
V_{h}=S_{\text {pist }} \cdot 2 \cdot S
$$

The instant cylinder volume is then obtained as following:

$$
V(x)=V_{h}-S_{p i s t} \cdot 2 \cdot x
$$

Here $\mathrm{x}=0$ is defined for the leftmost position of the left piston on

Figure 1. Besides, we have to take into account that the compression process starts in the cylinder only as soon as the gas exchange windows are closed. The pressure in the combustion chamber can be obtained as following:

$$
\left\{\begin{array}{l}
P(x)=P_{0}, \text { for } x_{\text {zvpo }}>x>0 \\
P(x)=\left(\frac{V\left(x_{\text {zvpo }}\right)}{V(x)}\right)^{k_{1}}, \text { for compression } \\
P(x)=P_{z}\left(\frac{V\left(x_{\epsilon}\right)}{V(x)}\right)^{k_{2}}, \text { for expansion }
\end{array}\right.
$$

where:

- $x_{z v p o}-$ the point where gaz exchange windows are closed,

- $\quad P_{0}$ - pressure in the cylinder during scavenging,

- $x_{\epsilon}-$ the point where the fuel mixture is ignited,

- $P_{z}=\lambda * P\left(x_{\epsilon}\right)$ - pressure in the cylinder during the ignition,

- $\lambda$ - pressure ratio,

- $k_{1}$ - compression polytrope factor,

- $\quad k_{2}$ - expansion polytrope factor.

\subsection{Electrical Machine Model}

On the first stage of the research, in order to simulate electromechanical part of the free piston generator, we used the same approach as in (Podoltsev \& Bondar, 2010). We use the similarity between rotating and reciprocating machines. This approach allows using Matlab/Simulink/SimPower rotating machine models as a linear machine. The development of the model of a real linear electrical machine is out of scope of this paper and is the matter of the future research.

The basic idea of the presented is that linear synchronous machines have the same construction as rotating synchronous machines, though it is rolled out in plane. Thus, electromagnetic processes in the linear machine correspond to those in rotating machines. The main characteristics of those processes will be similar if our model complies the following conditions:

- $\quad$ geometrical structure of the equivalent rotating machine is equal to that of the linear machine, i.e. their pole pitches $\tau$, pole pairs, lengths and widths of their active zones are equal;

- linear speed on the equivalent rotor equals to the linear speed of the translator:

$$
\omega_{r} R=v
$$

- mechanical powers are equal:

$$
T_{e} \omega_{r}=F_{e} v \Rightarrow F_{e}=T_{e} / R
$$

- $\quad$ kinetic energies of the moving parts of the machines are equal:

$$
\left(J \omega_{r}^{2}\right) / 2=m v^{2} \Rightarrow J=m R^{2}
$$

where: $\omega_{r}, T_{e}, J, R$ - angular rotation speed, electromagnetic torque, inertia torque and equivalent radius respectively; $v, F_{e}, m$ - linear translator speed, electromagnetic thrust, translator mass respectively. 
The value of the equivalent radius $R$ used in (3-5) can be obtained from the following equation:

$$
2 \pi R=2 p \tau
$$

The package Matlab/Simulink/SimPower implements the model of a permanent magnet synchronous machine using standard $d-q$ system of equations:

$$
\left\{\begin{array}{l}
\frac{d i_{d}}{d t}=\frac{u_{d}}{L_{q}}-\frac{R_{s} i_{d}}{L_{d}}+\frac{L_{q} p \omega_{r} i_{q}}{L_{d}} \\
\frac{d i_{q}}{d t}=\frac{u_{q}}{L_{q}}-\frac{R_{s} i_{q}}{L_{q}}-\frac{L_{d} p \omega_{r} i_{d}}{L_{q}}-\frac{\psi_{m} p \omega_{r}}{L_{q}} \\
T_{e}=1.5 p\left[\psi_{m} i_{q}+\left(L_{d}-L_{q}\right) i_{d} i_{q}\right]
\end{array}\right.
$$

where:

- $\quad L_{d}, L_{q}-d$ and $q$ axis inductances,

- $\quad R_{s}$ - stator winding resistance,

- $i_{d}, i_{q}-d$ and $q$ axis currents,

- $u_{d}, u_{q}-d$ and $q$ axis voltages,

- $\omega_{r}$ - angular velocity of the equivalent rotor,

- $\psi_{m}$ - amplitude of the flux induced by the permanent magnets of the rotor,

- $p$ - number of pole pairs,

- $T_{e}$ - electromagnetic torque.

We used the SimPower model PM Synchronous Motor Drive in order to simulate electromechanical part of the system. It incorporates a vector control system of the permanent magnet machine and a torque control input. During the simulation we set required torque to the drive, obtaining it from the required thrust using (4) and then recalculate translator velocity back using (5).

In order to measure the active power consumed or generated by the electrical machine, we use the following formulation:

$$
P_{e l}=\frac{3}{2}\left(V_{d} I_{d}+V_{q} I_{q}+2 V_{0} I_{0}\right)
$$

where:

- $P_{e l}$ - electrical active power,

- $V_{d}, V_{q}, V_{0}$ - voltages in $d q 0$ frame,

- $I_{d}, I_{q}, I_{0}-$ currents in $d q 0$ frame.

The entire model is described later in this paper.

\section{Mechanical equations}

The pressure model of the free piston engine and electromechanical model of its generator are connected using the following mechanical equations:

where:

$$
F_{p i s t}+F_{\text {fric }}+F_{\text {ext }}=m \frac{d^{2} x}{d t^{2}}
$$

- $F_{\text {pist }}$ - forces produced by the piston,

- $F_{\text {fric }}$ - friction forces,

- $\quad F_{\text {ext }}-$ external forces, i.e. the thrust produced by linear machine,

- $m$ - complete translator and piston mass,

- $x$-coordinate,

- $t$ - time.

In particular, force produced by the piston is calculated as following: 


$$
F_{\text {pist }}=\frac{P(x)}{S_{\text {pist }}}
$$

where $P(x)$ is obtained from (2).

The friction force is caused by the friction between the piston rings and the inner cylinder walls. Since the piston and the translator have linear movement in the free piston engine, there is no relaying of the piston inside the cylinder, which is regular for traditional engines. Hence, the friction in the cylinder-piston group is caused only by the pressure force between the piston rings and the inner cylinder walls. The friction of the bearings can be neglected. Thus, the friction force can be assumed as following:

$$
F_{\text {fric }}=m g k_{f}(-\operatorname{sign}(v))
$$

where:

- $g$ - gravity $\left(9.81 \mathrm{~m} / \mathrm{s}^{2}\right)$,

- $k_{f}$ - friction factor,

- $\quad v$-translator velocity.

\section{Control Formulation}

In order to achieve the goal of controlling TDC and BDC in our model, we use the thrust control of the electrical drive. The thrust (force) that is required from the drive is calculated in accordance with the model of the free piston engine, described in this paper.

The method that we propose is based on the following statements:

1) During the first parts of the compression and expansion phases the required thrust is constant.

2) During the last parts of the compression and expansion phases the required acceleration (breaking) is constant.

3) During the compression phase the translator velocity is limited.

The first statement is quite clear to implement and the values of the force of compression and breaking force of expansion are limited by the power demands of the system.

The second statement represents the rule that we must breakdown to the required point (TDC or BDC) and it is based on the basic mechanical formulation that:

$$
\left\{\begin{array}{c}
a=\frac{v_{\mathrm{i}}}{t_{b r}} \\
\Delta x=\frac{a t_{b r}^{2}}{2}
\end{array}\right.
$$

where:

- $\quad a$-acceleration (breaking),

- $v_{i}$-speed in the current simulation point,

- $t_{b r}$ - time of breaking,

- $\Delta x$ - distance that we have for breaking.

Solving (10) for the unknown acceleration $a$ we define then:

$$
a=\frac{v_{i}^{2}}{\Delta x}
$$

Thus, we define the limits when the electrical machine starts breaking and calculate the required thrust as following:

$$
F_{\text {ext }}=a m-F_{\text {pist }}-F_{\text {fric }}
$$

The value of $a$ is calculated by (11) and the value of $\Delta x$ is obtained as following:

where:

$$
\Delta x=x_{\text {stop }}-x_{i}
$$

- $x_{i}$ - current position of the piston, 
- $x_{\text {stop }}$ - required stop position, which can be either TDC or BDC.

\section{Simulink Model and Simulation Results}

\subsection{Model Description}

The entire system was created and simulated in the Matlab/Simulink software with the help of SimPower library, which was used to simulate electrical drive. The model structure is presented in the Figure 2.

Due to size of the entire free piston model diagram, it cannot be shown in the paper. Thus, we present the global block diagram and discuss some internal blocks. The main diagram of the system consists of the blocks representing logical structure of the system: free piston engine simulation block, electrical system blocks (electric drive model), linear-rotation conversion block, required force calculation and integration block.

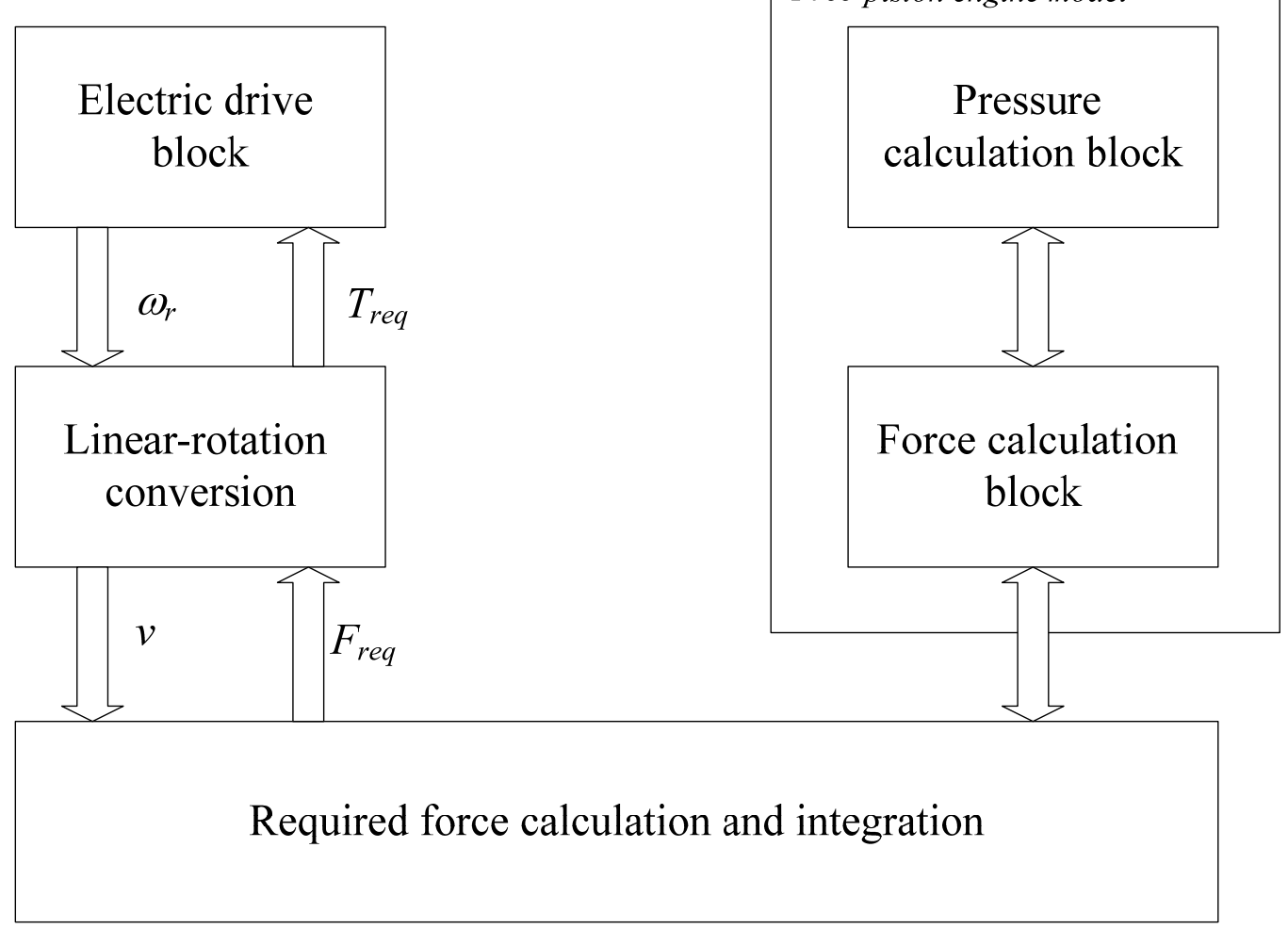

Figure 2. Simulink model structure

Free piston block consists of the pressure calculation block in accordance with (2) and friction force calculation block (9). Entire force is obtained using (8).

The free piston model is based on the pressure calculation block that implements the (2). The block is shown in the Figure 3. It calculates the pressure in the cylinder for the current piston position and the compression mode. The calculation of the pressure takes into account the exhaust window size. The pressure drops down to the specified value as soon as the exhaust window is open, i.e. the piston achieved specified position.

The results of the pressure calculations are further used to obtain forces produced by the piston in accordance to the current compression mode and current piston position. The mechanical movement equations are solved in the integration block. 


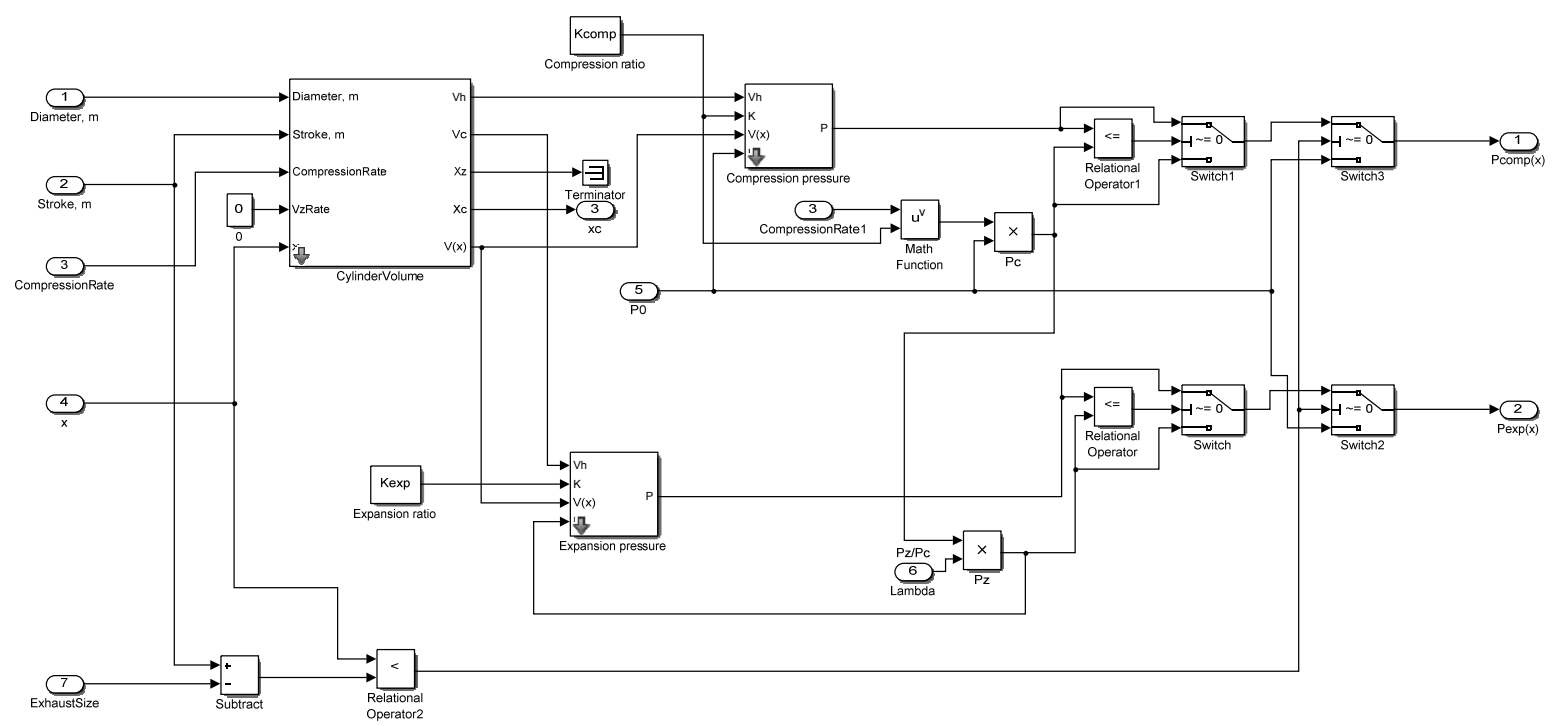

Figure 3. Pressure calculation

A part of the model, describing electromechanical part of the system is presented in the Figure 4. It contains the Simulink model of a complete permanent magnet machine drive using vector control technique.

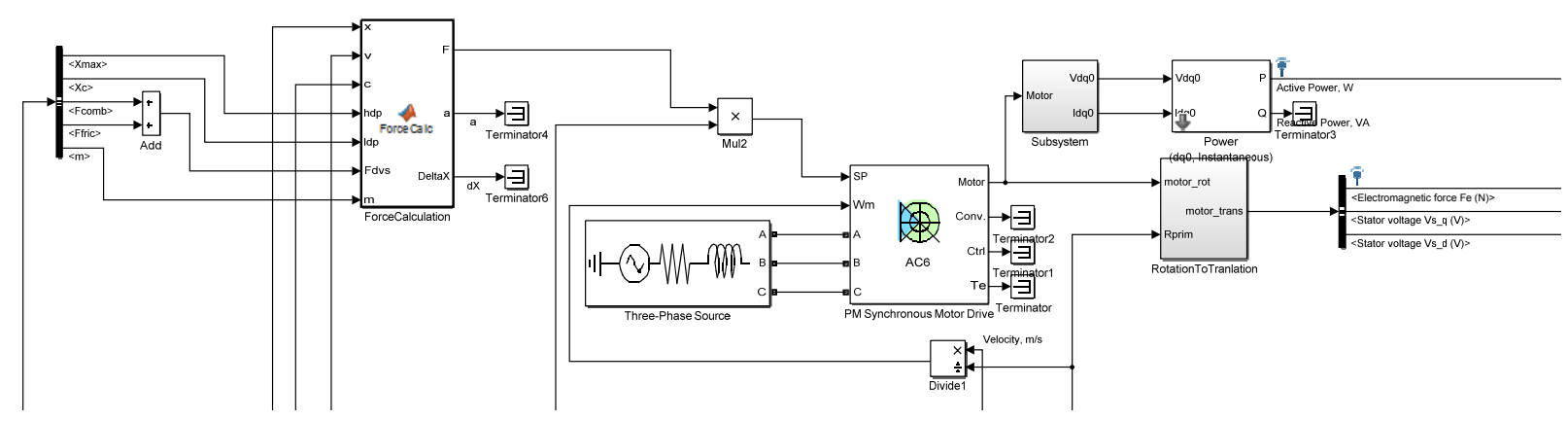

Figure 4. Electromechanical part of the model

The block implements the drive that can function both in torque control and in speed control modes. For our purposes, we use torque control that leads to thrust control after the conversions discussed above in the paper. The torque set point of the drive is derived from the (12). Its calculation depends on the following variables: current piston position, current mode (either compression or expansion), current velocity; and the following parameters: piston and translator mass, TDC and BDC. The electrical drive block returns rotational and electrical parameters of the machine that are converted into linear movement parameters and further used with the free piston model. The electrical power consumed or produced by the drive is then calculated by (7) using dq-frame variables.

The signals of the piston coordinate, velocity, acceleration and generated active power are stored in the output variables, which are used for post-processing.

\subsection{Simulation Results}

The simulation was performed for the parameters of the free piston engine and electrical drive presented below in the 0 
Table 1. Parameters of the Simulation System

\begin{tabular}{cr}
\hline Parameter & Value \\
\hline Piston diameter, $\mathrm{mm}$ & 75.6 \\
Piston stroke, $\mathrm{mm}$ & 82 \\
Piston mass, $\mathrm{kg}$ & 0.5 \\
Translator mass, $\mathrm{kg}$ & 9.5 \\
Compression ratio & 13 \\
Machine stator resistance, Ohm & 0.01028 \\
Pole pairs & 6 \\
$\mathrm{~L}_{\mathrm{d}}, \mathrm{mH}$ & 11 \\
$\mathrm{~L}_{\mathrm{q}}, \mathrm{mH}$ & 11 \\
Rated compression force, $\mathrm{N}$ & 4000 \\
Rated expansion (breaking) force, $\mathrm{N}$ & 7000 \\
Relative point on breaking before TDC or & \\
BDC, \% of stroke & 20 \\
Speed limit in compression phase, $\mathrm{m} / \mathrm{s}$ & 1.5 \\
\hline
\end{tabular}

During the simulation, we obtained several periods of reciprocation and the speed diagram is shown in the Figure 5.

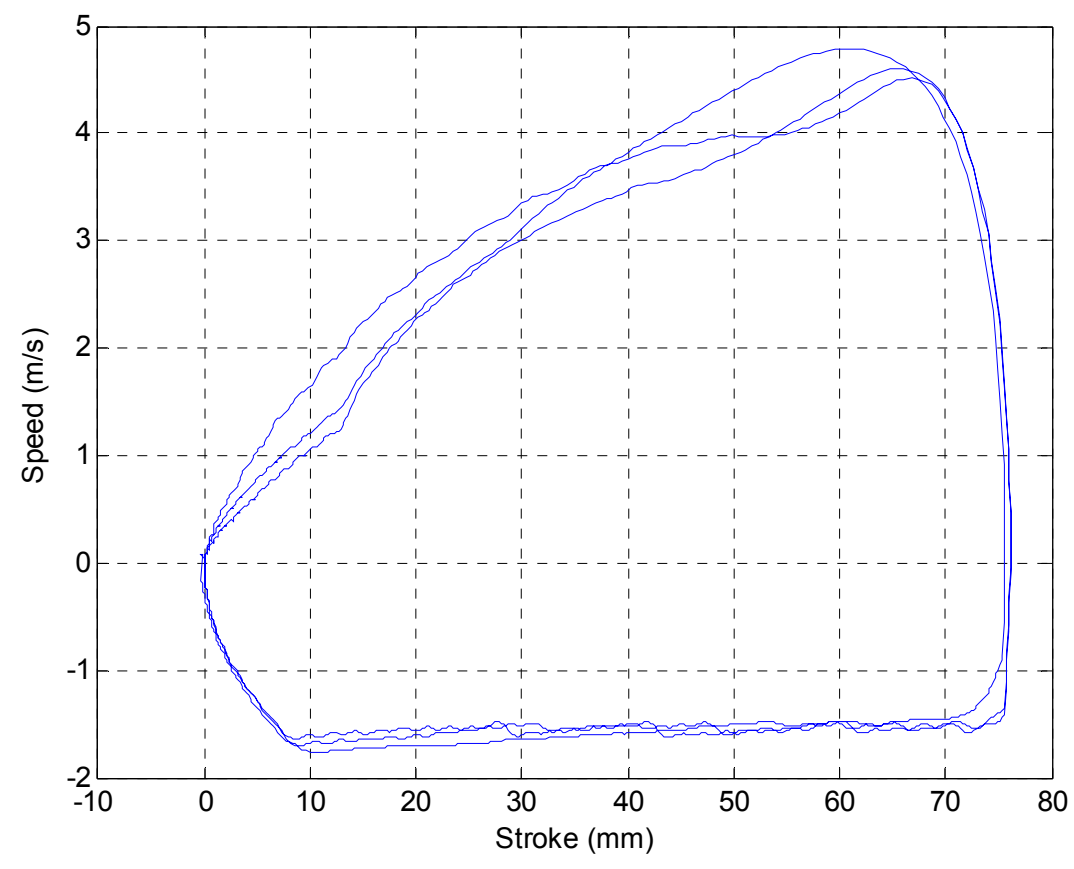

Figure 5. Speed diagram

The leftmost and rightmost points correspond to the BDC and TDC respectively. The first two cycles show up the startup of the reciprocation. Starting from the third cycle the movement becomes steady. The limitation of the speed in compression phase is visible as a relatively flat zone in the bottom of the diagram. That limitation allows controlling the TDC point more accurately. TDC $\left(x_{\epsilon}=0.0761\right)$ corresponds to the defined compression ratio. The $\mathrm{BDC}(\mathrm{x}=0)$ is very well controlled.

The total generated power was calculated using the following equation:

$$
P_{g e n}=\int_{0}^{T_{e}} P_{e l}(t) d t
$$

where $P_{e l}(t)$-instant active power (7), $T_{e}$ - the end time of the last period, when $x_{e}=0$. 
The calculation by (13) give the value of $P_{g e n}=-9.071 \mathrm{~kW}$. The negative sign means that the power was generated, not consumed.

The simulation was performed only for one side machine, though obtaining all the pressures for the engine presented in the

Figure 1. So, the obtained power should be doubled for two machines. The synchronization between two electrical machines is out of scope of this paper.

\section{Conclusions}

We presented the approach that allows controlling the TDC and BDC positions of the pistons in the free piston engine without mechanical boundary limits. The approach is quite simple and is based on the calculation of breaking forces on the last parts of the compression and expansion phases of a reciprocating period. The simulation in Matlab/Simulink showed good results and stable generation of energy. Though this approach was tested with the opposed piston free piston engine model, it is quite suitable for any other types of free piston engines.

Anyway, this paper does not touch the aspects of synchronization between two electrical machines working together with opposed piston free piston engine, along with the study of different free piston engine types. The implementation of the model of a linear electrical machine in Matlab/Simulink and the influence of the ignition timing on the performance of the presented control approach are out of scope of this paper as well. This is the subject for the future research.

\section{Acknowledgements}

This paper was prepared under grant agreement No.14.577.21.0100 (unique identifier of the project RFMEFI57714X0100) with financial support from the Ministry of Science and Education of the Russian Federation. The research is being held at the Federal State Educational Institution of Higher Professional Education "Moscow state university of mechanical engineering (MAMI)".

\section{References}

Carter, D., \& Wchner, E. (2003). The Free Piston Power Pack: Sustainable Power for Hybrid Electric Vehicles. SAE Technical Paper. http://dx.doi.org/10.4271/2003-01-3277

Ferrari, C., \& Friedrich, H. E. (2012). Development of a Free-Piston Linear Generator for use in an Extended-Range Electric Vehicle. EVS26 International Battery, Hybrid and Fuel Cell Electric Vehicle Symposium. Los Angeles, California.

Goldsborough, S., \& Van Blarigan, P. (2001). Optimizing the scavenging system for a two-stroke cycle, free piston engine for high efficiency and low emissions: A computational approach. SAE Paper, 2001-01-0280.

Goto, S., Moriya, K., Kosaka, H., \& Akita, T. (2014). Development of Free Piston Engine Linear Generator System Part 2 - Investigation of Control System for Generator. SAE Technical Paper(2014-01-1193).

Hibi, A., \& Ito, T. (2004). Fundamental test results of a hydralic free piston internal combustion engine. Proc. Inst. Mech. Eng., (218), 1149-1157.

Huang, L. (2012). An Opposed-Piston Free-Piston Linear Generator Development for HEV. SAE Technical Paper(2012-01-1021). http://dx.doi.org/10.4271/2012-01-1021

Ibrahim, A., Aziz, A., Abidin, E., \& Zulkifi, S. (2011). The operation of free piston linear generator engine using MOSFET and IGBT drivers. Journal of Applied Sciences (in-press).

Kock, F., Haag, J., \& Friedrich, H. (2013). The Free Piston Linear Generator - Development of an Innovative, Compact, Highly Efficient Range-Extender Module. SAE Technical Paper. http://dx.doi.org/10.4271/2013-01-1727

Kosaka, H., Akita, T., Moriya, K., Goto, S., Hotta, Y., Umeno, T., \& Nakakita, K. (2014). Development of Free Piston Engine Linear Generator System Part 1 - Investigation of Fundamental Characteristics. SAE Technical Paper, 2014-01-1203. http://dx.doi.org/10.4271/2014-01-1203

Larmi, M., Isaksson, S., Tikkanen, S., \& Lamiila, M. (2001). Performance simulation of a compression ignition free piston engine. SAE Paper, 2001-01-0280.

Li, L., Luan, Y., Wang, Z., \& Deng, J. (2010). Simulations of Key Design Parameters and Perfomace Optimization for a Free-piston Engine. SAE Technical Paper. http://dx.doi.org/10.4271/2010-01-1105

Mikalsen, R., \& Roskilly, A. (2007). A review of free-piston engine history and applications. Applied Thermal 
Engineering, (27), 2339-2352.

Mikalsen, R., \& Roskilly, A. (2008). The desing and simulation of a two-stroke free-piston compression ignition engine for electrical power generation. Applied Thermal Engineering, 28, 589-600.

Mikalsen, R., \& Roskilly, A. (2010). The control of a free-piston engine generator. Part 2: Engine dynamics and piston motion control. Applied Energy, (87), 1281-1287.

Nemecek, P., Sindelka, M., \& Vysony, O. (2006). Ensuring Steady Operation of Free-Piston Generator. Journal of Systems, Cybernetics and Informatics, 1(4), 19-23.

Podoltsev, A., \& Bondar, R. (2010). Modeling of a linear three-phase synchronous motor. Electrotechnics and Electromechanics, $\operatorname{Kiev}(6)$.

Pohl, S., \& Graf, M. (2005). Dynamic Simulation of a Free-Piston Linear Alternator in Modelica. Proceedings of the 4th International Modelica Conference (pp. 393-399). Hamburg.

Shourky, E., Taylor, S., Clark, N., \& Famouri, P. (2002). Numerical simulation for parametric study of a two-stroke direct injection linear engine. SAE Paper.

Waqas, M. A., Backstrom, T., Thelin, P., \& Sadarangani, C. (2002). Integrated free-piston generators: An overview. Electrical Vehicle Symposium.

Zhaoping, X., \& Siqin, C. (2010). Prototype testing and analysis of a novel internal combustion linear generator integrated power system. Applied Energy, 87, 1342-1348. http://dx.doi.org/10.1016/j.apenergy.2009.08.027

Zulkifli, S. A., Karsiti, M. N., \& A-Aziz, A. R. (2009). Investigation of Linear Generator Starting Modes by Mechanical Resonance and Rectangular Current Commutation. Electric Machines and Drives Conference (pp. 425-433). http://dx.doi.org/10.1109/OEMDC.2009.5075241

\section{Copyrights}

Copyright for this article is retained by the author(s), with first publication rights granted to the journal.

This is an open-access article distributed under the terms and conditions of the Creative Commons Attribution license (http://creativecommons.org/licenses/by/3.0/). 